\title{
COMMENTARY
}

\section{Hippocampal Involvement in Contextual Modulation of Fear Extinction}

\author{
Jinzhao $\mathrm{Ji}^{1}$ and Stephen Maren ${ }^{1,2 *}$
}

\begin{abstract}
Extinction of fear conditioning in animals is an excellent model for the study of fear inhibition in humans. Substantial evidence has shown that extinction is a new learning process that is highly context-dependent. Several recovery effects (renewal, spontaneous recovery, and reinstatement) after extinction suggest that the contextual modulation of extinction is a critical behavioral mechanism underlying fear extinction. In addition, recent studies demonstrate a critical role for hippocampus in the context control of extinction. A growing body of evidence suggests that the hippocampus not only plays a role in contextual encoding and retrieval of fear extinction memories, but also interacts with other brain structures to regulate context-specificity of fear extinction. In this article, the authors will first discuss the fundamental behavioral features of the context effects of extinction and its underlying behavioral mechanisms. In the second part, the review will focus on the brain mechanisms for the contextual control of extinction. ๑ 2007 Wiley-Liss, Inc.
\end{abstract}

KEY WORDS: fear conditioning; extinction; context; behavioral mechanisms; brain mechanisms; hippocampus; amygdale; prefrontal cortex

\section{INTRODUCTION}

In the context of normal human life, fearful situations are regularly encountered; characteristically, these are managed successfully and then forgotten. However, in some individuals, the fearful situation is overwhelming, such as military combat, motor vehicle accident, or sexual assault. These fearful experiences persist and contribute to, such as, psychological disturbances, post-traumatic stress disorders (PTSD), and panic disorders (Friedman et al., 1994; Maren and Chang, 2006; Feldner et al., 2007). Understanding the precise neural mechanisms of anxiety is necessary for developing selective and effective treatments.

Pavlovian fear conditioning and its extinction are the most extensively studied models that provide the laboratory tools to understand the neural mechanisms of fear and anxiety disorders in humans (Myers and Davis, 2002; Kim and Jung, 2006). Pavlovian fear conditioning is a

\footnotetext{
${ }^{1}$ Department of Psychology, University of Michigan, Ann Arbor, Michigan; ${ }^{2}$ Neuroscience Program, University of Michigan, Ann Arbor, Michigan

*Correspondence to: Stephen Maren, Department of Psychology, University of Michigan, 530 Church Street, Ann Arbor, MI 48109-1043, USA. E-mail: maren@umich.edu

Accepted for publication 2 May 2007

DOI 10.1002/hipo.20331

Published online 29 June 2007 in Wiley InterScience (www.interscience. wiley.com).
}

form of associative learning, in which an animal (typically a rat) is exposed to pairings of a neutral conditional stimulus (CS), such as a tone or light, with an aversive unconditional stimulus (US), such as a footshock; this procedure yields a conditioned fear response to the CS. Extinction training, in which CSs are repeatedly presented in the absence of USs, suppresses the amplitude and probability of the conditional response (Pavlov, 1927). As a result, an animal learns that a CS no longer predicts that aversive US. Since Pavlov (1927) observed that extinguished conditional response could recover with the passage of time, extinction has been widely interpreted not to be a process of erasing the original excitatory association (i.e., CS-US), but instead a process of learning a new inhibitory association (i.e., CS-no US) (Myers and Davis, 2002; Bouton, 2004; Delamater, 2004). By the competition between an inhibitory CS-"no-US" association and excitatory CS-US association, the conditional fear response is suppressed (Myers and Davis, 2002; Bouton, 2004; Delamater, 2004).

During this competition, context appears to play an important role to modulate the suppression of extinction memories (Bouton, 2002, 2004). For example, one of the fundamental context effects is the renewal effect, in which changing the context favors recall of extinguished fear memory (Bouton, 1993, 1994). Other context effects of extinction include spontaneous recovery and reinstatement, in which an extinguished response can be recovered following the passage of time or re-exposure to an unsignaled US in a relevant context (Myers and Davis, 2002; Bouton, 1993, 1994). These behavioral features of extinction therefore indicate that extinction involves new learning that is particularly dependent on context.

In this review, we will first summarize some fundamental behavioral features of context effects in extinction, and discuss behavioral mechanisms underlying contextual modulation of fear extinction. Since there is a growing body of research uncovering the neural mechanisms enabling this modulation, in the second part, we will discuss the data concerning the roles of the brain structures that mediate the context-specific expression of extinction, especially the involvement of hippocampus, and hippocampal interactions with pre- 
frontal cortex and amygdala network in the contextual regulation of extinction.

\section{BEHAVIORAL MECHANISMS OF EXTINCTION}

\section{New Learning Rather than Erasure Process}

Considerable evidence has emerged to show that extinction does not erase original learning but instead is an active learning process. There are three impressive behavioral features of extinction (including renewal, spontaneous recovery, and reinstatement) that favor the view that extinction is a form of new learning. In each case, the extinguished conditional response returns after extinction. One property of extinction, known as the renewal effect, has been extensively studied. In this phenomenon, an extinguished conditional response returns if the CS is presented outside of the extinction context in animals (Bouton and Bolles, 1979a; Bouton and King, 1983) or humans (Rodriguez et al., 1999). Another effect is spontaneous recovery, in which the extinguished conditional response recovers with a passage of time after extinction (for reviews, see Robbins, 1990; Brooks and Bouton, 1993). The third phenomenon is reinstatement, in which an extinguished conditional response is partially restored if the subject is exposed to the US alone following extinction (e.g., Rescorla and Heth, 1975; Bouton, 1993, 2002). Both renewal and spontaneous recovery indicate that a CS retains its ability to drive conditional responding following extinction, and must therefore retain at least some of the strength it acquired upon being paired with an US. In reinstatement, contextual conditioning after extinction can reinstate fear to the CS suggesting that extinction does not destroy the CS-US association. Therefore, all these behavioral features indicate that extinction does not erase the original CS-US association. Meanwhile, all of these phenomena indicate that the expression of extinction memories is also context-dependent (Bouton 1993, 2002). Extinction involves new learning; therefore, it leaves the CS with two available "meanings" or associations with the US.

\section{Context-Dependence of Fear Extinction Memory}

\section{Renewal}

The renewal effect is perhaps the most fundamental and impressive context effect in extinction. There are several different forms of renewal effects, including $A B A, A A B$ and $A B C$ renewal (each letter denotes conditioning, extinction, or testing context). Thus, in ABA renewal, conditioning (CS-US pairings) occurs in context $A$, extinction (CS presentation in the absence of US) in context $B$, and then CS is tested in original conditioning context (context $\mathrm{A})$. In $\mathrm{AAB}$ or $\mathrm{ABC}$ renewal, all retrieval testing is conducted outside of the conditioning context as well as occurred in a context different from the extinction, in that the CS is tested in a neutral context that has no history of CS exposure. However, whether the animal is presented an extinguished $\mathrm{CS}$ in the conditioning context $(\mathrm{ABA})$ or in a neutral context ( $\mathrm{AAB}$ or $\mathrm{ABC})$, renewal is demonstrated by greater conditional response relative to the extinction context (AAA or ABB). Hence, the expression of extinction is contextdependent (Bouton, 2004; Bouton et al., 2006).

The renewal effect has been demonstrated in many conditioning paradigms (Bouton, 1994, 2002; Bouton et al., 2006). It has been demonstrated in appetitive conditioning (Brooks and Bouton, 1994), taste aversion learning (e.g., Rosas and Bouton, 1998; Chelonis et al., 1999), and operant conditioning (for review, see Nakajajima et al., 2000; Bouton, 2002), as well as fear conditioning (e.g., Bouton and Swartzentruber, 1989; Wilson et al., 1995; Frohardt et al., 2000; Corcoran and Maren, 2001, 2004; Ji and Maren, 2005). It has also been demonstrated in a causal judgment task in humans (Rosas et al., 2001). In addition, it appears that the renewal effect can be induced by many kinds of contexts. In one experiment, for example, alcohol was used as an intereroceptive drug "context" (Cunningham, 1979). In another experiment, Bouton et al. (1990) obtained similar results that extinction under the influence of benzodiazepine tranquilizers renewed when rat was tested in a drug-free state. Moreover, administration of adrenocorticotropic hormone prior to testing yields renewal of fear in the avoidance performance when rats are returned to the hormonal conditional context (Richardson et al., 1984; Ahlers and Richardson, 1985). All of these observations suggest that the renewal effect is fairly general.

The renewal effect is not only well studied in animals but has also been studied in humans (Mineka et al., 1999; Rodriguez et al., 1999; Rosas et al., 2001; Kalisch et al., 2006). In one study, a causal judgment task in humans was shown to be modulated by context after retroactive interference (extinction) (Rosas et al., 2001). In another experiment, Rodriguez et al. (1999) examined the context-specificity of fear extinction among the patients undergoing exposure treatment for spider phobia. The results demonstrated a context-specific return of fear after the exposure session. The renewal effect is also very robust. In fear conditioning (bar suppression), Bouton and Swartzentruber (1986) observed it after 84 extinction trials following eight conditioning trials. Corcoran and Maren (2001) and others (Gunther et al., 1998; Rauhut et al., 2001) found it occurred after as many as 180 extinction training trials, although Denniston et al. (2003) have reported that "massive" extinction training with 800 trials eliminates renewal.

Some models have been proposed to illustrate the behavioral mechanisms underlying contextual modulation of extinction. One model is that contextual stimuli can modulate the performance of Pavlovian conditional response in extinction (Bouton, 1993, 1994). According to Bouton (1994), an association between a CS and an US is formed during conditioning. In extinction, a new inhibitory CS-"no US" association that is formed blocks the activation of the original CS-US association, thereby limiting the conditional responding to the CS. The meaning of the CS is now ambiguous, and requires the context to disambiguate the meaning of extinguished CS. That is, the excitatory CS-US association established during conditioning is not context-specific and generalizes in all test 
contexts. In contrast, the inhibitory CS-"no US" association established during extinction is context-specific. Therefore, the inhibitory association is "gated" so that its activation requires the simultaneous presence of the CS and the extinction context. This "gated" activation allows the expression of inhibitory association memory when the CS is presented in the extinction context. In contrast, presenting the CS outside of the extinction context would reduce activation of the inhibitory link, therefore causing a renewal of conditional response to the CS (Bouton, 1994).

Similar to the "gating" model, context may be "on occasion setter" for the current CS-US or CS-"no US" associations (Bouton and Swartzentruber, 1986; Holland, 1992). In negative occasion setting, a discrete cue stimulus (the feature) precedes a CS (a target) stimulus when the US does not follow the target. Hence, the extinction context may act as a "negative occasion setter" by signaling the CS not followed by the US (Bouton, 1993). In situations in which a CS acquires multiple meanings (both an excitatory CS-US association and an inhibitory CS-"no-US" association after extinction training), retrieval context serves as the feature or occasion setter for the selective retrieval of the appropriate meaning of the target CS (Bouton, 1993).

Another view is that the context can serve as another CS, in addition to participating in contextual encoding and retrieval. That is, contexts themselves can signal US and enter into compound associations or configurations with other stimuli (Rescorla and Wagener, 1972; Pearce and Hall, 1980; Wagner and Brandon, 1989). It therefore enters into simple excitatory or inhibitory associations with US during conditioning or extinction. In the $\mathrm{ABA}$ renewal, for example, context $\mathrm{B}$ might acquire inhibitory associations with US during extinction, and context A might acquire excitatory associations. Either kind of association would summate with the CS to produce extinction and renewal performance in the extinction and conditioning contexts, respectively. Nevertheless, a context does not need to acquire excitatory or inhibitory associative strength itself to modulate conditional response. That is, the context-specific expression of Pavlovian memories is not simply because of excitatory or inhibitory context-US associations, but rather can occur in the absence of the demonstrable excitation in context (A) or inhibition in context (B) (Bouton and King, 1983; Bouton and Swartzentruber, 1986; Bouton et al., 2006). Nonetheless, the context specificity of memory might arise from the configurative or conjunctive association of a context with a CS (O’Reilly and Rudy, 2001).

\section{Spontaneous recovery}

One of Pavlov's most famous discoveries was the return of conditional responding with the passage of time (Pavlov, 1927). Pavlov noted that if time elapses after extinction, the extinguished response could recover "spontaneously" when CS was tested again. There are several basic empirical properties of spontaneous recovery that are widely accepted. First, spontaneous recovery, similar to the renewal effect, has been dem- onstrated in virtually every conditioning method (for review, see Brooks et al., 2001). Moreover, spontaneous recovery has been well documented to increase in a negatively accelerated fashion over time (Rescorla, 2004). That is, the longer the delay between extinction termination and testing, the greater the recovery. This feature has been found in fear conditioning in rats (Quirk, 2002), eyelid conditioning in rabbits (Haberlandt et al., 1978), and sign-tracking in pigeons (Robbins, 1990). In addition, recovery declines with repeated extinction (Rescorla, 2004).

Although there are several models available to explain spontaneous recovery, it can be viewed as a forum of contextdependent inhibitory learning (Bouton, 1993, 1994). According to memory theorists (e.g., Spear, 1981), the passage of time may provide a gradually changing context (also see Bouton, 2004). Given this possibility, Bouton (1993) has argued that just as extinction is spatial context specific in renewal, it might also be "temporal context" specific in the spontaneous recovery. In the "gating" mechanism proposed by Bouton (1994), if the CS is associated with the passage of time (temporal context), the model also predicts spontaneous recovery. As time passes after extinction (temporal context gradually changes), shifts in temporal context would reduce the activation of the inhibitory association, leading to the occurrence of spontaneous recovery. Therefore, spontaneous recovery is another "renewal effect", that occurs when the CS is tested outside its "temporal extinction context", relative to the "physical context" (Bouton, 1993, 1994).

This idea suggests that both renewal and spontaneous effects are controlled by a common mechanism: a failure to retrieve a memory of extinction outside of the extinction context (Bouton, 2004; Bouton et al., 2006). If this is true, either effect should be attenuated if a retrieval cue that reminds the subjects of extinction memories is presented just prior to the recovery test. It appears that there have been several studies supporting this view. For example, Brooks and Bouton (1993) and Brooks (2000) presented a brief visual cue intermittently during extinction and then presented the cue before the retrieval testing long after extinction. The results showed that the cue presentation prior to testing attenuated spontaneous recovery. Importantly, a reduced renewal effect was also found when a similar retrieval cue was presented before testing outside of the extinction context (Brooks and Bouton, 1994). These data suggest that renewal and spontaneous recovery result from a similar control mechanism, which is due to the failure to retrieve a memory of extinction outside of the extinction context (Bouton, 2004). In another experiment, animals with both temporal and spatial context shifts after extinction showed a stronger recovery of extinguished responding than after either manipulation alone (Rosas and Bouton, 1998). This indicates that the spatial and temporal contexts produce similar effects in modulation of extinction, further supporting the view that renewal and spontaneous recovery share a common mechanism (Bouton, 2004).

A recent study extends the idea of temporal context by examining the interaction of temporal context and extinction 
intertrial interval (ITI) (Bouton and Garcia-Gutierrez, 2006). In this study, it was hypothesized that extinction ITI might be encoded as the extinction context, and the interaction of the ITI and retention interval (temporal context) could modulate extinction memories. If the last extinction trial shifted the temporal context, spontaneous recovery might occur. The results confirmed this hypothesis in that rats receiving 4-min ITI extinction trials showed spontaneous recovery when presented with a 16-min ITI during the retention test. However, other rats that received 16-min ITI extinction trial failed to show recovery in this test. Therefore, ITI might also be encoded as part of the context to modulate extinction memories. However, further study demonstrated that spontaneous recovery did not occur if a longer extinction ITI was followed by a shorter temporal context (i.e., 16-min ITI followed by a 4-min ITI) despite that the intervals are mismatched (for review, see Bouton et al., 2006).

\section{Reinstatement}

In addition to renewal and spontaneous recovery, the extinguished response returns after extinction if the animal is merely re-exposed to the US alone (Pavlov, 1927; Rescorla and Heth, 1975; Bouton and Bolles, 1979b). In a typical fear reinstatement task, animals first undergo conditioning and extinction. Following extinction, an aversive US is presented a few times in a distinct context. When fear to the CS is tested again, the conditional response is reinstated (Bouton and Bolles, 1979b; Bouton, 1993, 2002). In this case, evidence strongly suggests that the reinstatement effect is due to context conditioning. The context-US associations after extinction promote reinstatement (Bouton, 1993, 2004). Similar to renewal and spontaneous recovery, reinstatement also demonstrates the context-dependence of extinction. That is, reinstatement only occurs when the USs are presented in the context, in which the extinguished CS is tested but not when reinstating USs are presented in a novel or irrelevant context (Bouton and Bolles, 1979b; Bouton and King, 1983; Bouton, 1984; Wilson et al., 1995; Frohardt et al., 2000; Bouton, 2004).

Besides the context-specificity of extinction, there are several other empirical properties in reinstatement. The first one is that the strength of reinstatement is correlated with the strength of contextual conditioning (Bouton and King, 1983; Bouton, 1984, 2004). The second one is that reinstatement is attenuated by exposure to the context, in which reinstatement shock was delivered (Bouton and Bolles, 1979b; Baker et al., 1991; Bouton, 1993). The third property is that the reinstatement shock has a stronger effect on extinguished CSs compared with nonextinguished CSs (Bouton, 1984, 1993). For example, Bouton (1984) delivered reinstatement shock in the same or different context under a comparable condition, in which the fear of one group of rats was partially extinguished; whereas the other group of rats reached the same level of fear by simple CS-US conditioning but without extinction. The data showed that contextual conditioning resulted in an impressive reinstatement for the extinguished CS, but had no discernable effect on performance to a nonextinguished CS (Bouton and King, 1986).

The results that extinguished CSs are particularly sensitive to contextual control suggest that the reinstatement may be due to a similar mechanism underlying other context effects of extinction (i.e., renewal and spontaneous recovery) (Bouton, 1993). Bouton (1993) proposed that contextual conditioning may constitute part of a background associated with conditioning and thus may act as another feature of the conditioning "context". When extinguished CS is returned to that conditioning context, a feature of the conditioning "context" will activate the original CS-US memory, leading to the reinstatement of extinguished conditional responding, just like another ABA renewal (Bouton, 1993, 2004).

THE BRAIN MECHANISMS UNDERLYING CONTEXT DEPENDENCE OF EXTINCTION

\section{Hippocampus}

As theoretical studies in conjunction with recent empirical discoveries reveal a role of context in regulating expression of extinction, it has become important to understand the brain mechanisms underlying the contextual control of extinction. Considering the established role of the hippocampus in several memory processes, including episodic memory (Squire and Zola, 1996; Eichenbaum, 2000, 2001; Burgess et al., 2002), researchers have began to explore how it mediates context effects on learning.

Hirsh (1974) proposed one of the first theories to account for context effects in memories. He suggested that the hippocampus was a critical substrate for contextual memory retrieval (Hirsh, 1980; Ross et al., 1984; Good and Honey, 1991; Honey and Good, 1993; Holt and Maren, 1999). Meanwhile, an abundance of evidence reveals that the hippocampus is also involved in encoding and consolidating representations of contexts, as well (e.g., Kim and Fanselow, 1992; Philips and LeDoux, 1992; Antagnostaras et al., 1999). Therefore, it is believed that the hippocampus is critical for using contextual representations to guide behavior (Rudy and O'Reilly, 1999, 2001; Fanselow, 2000; Maren and Holt, 2000). Based on these findings, the hippocampus has been explored for its role in contextual modulation of extinction.

\section{Hippocampal involvement in context-dependent retrieval after extinction}

As a first attempt to examine the role of the hippocampus in contextual modulation of extinction, Wilson et al. (1995) made permanent lesions of the fimbria/fornix prior to conditioning and observed its influence on several context effects after extinction, including renewal, spontaneous recovery, and reinstatement. The results showed that rats with hippocampal lesions did not show reinstatement, but exhibited normal in 
renewal and spontaneous recovery. This result was subsequently replicated in another experiment (Frohardt et al., 2000), showing that complete hippocampal lesions made before conditioning interfered with the reinstatement to fear to an extinguished CS, but left renewal of fear to an extinguished CS intact. These two studies suggest that the hippocampus is not necessary for the context-specific expression of extinguished fear. However, these conclusions are tempered by the fact that all these studies used permanent pretraining lesions of the hippocampus, which necessarily confound the hippocampal role in retrieval processes with its possible role in encoding process (Maren et al., 1997; Maren and Holt, 2000). To overcome these problems, Corcoran and Maren (2001) reversibly inactivated the dorsal hippocampus (DH) with muscimol, a gamma-aminobutyric acid receptor agonist prior to retention testing and examined its effect on context-dependent expression of extinction. In this experiment, intact rats exhibited context-specific retrieval after multiple extinction training sessions, in that they displayed low levels of freezing when presented in the extinction context but showed high levels of freezing when tested outside of the extinction context. The renewal of fear by the context shift was so robust that the elevated fear reached a similar level to that in nonextinguished rats. However, intrahippocampal muscimol infusions prior to testing disrupted this context-specificity, eliminating the renewal of fear to an extinguished CS that occurred outside of the extinction context. This experiment strongly suggests, in contrast to the earlier work (Wilson et al., 1995; Frohardt et al., 2000), that the hippocampus is involved in the context-dependent expression of extinction.

One factor that might account for this discrepancy is that Corcoran and Maren (2001) used an ABC renewal design (Experiment 2), whereas Bouton and colleagues used an ABA design (Wilson et al., 1995; Frohardt et al., 2000). It remains a question, therefore, whether hippocampal lesions influence different types of contextual control in different ways. To address this question, Corcoran and Maren (2004) examined the role of the hippocampus in different renewal paradigms. Consistent with their earlier findings, muscimol inactivation of $\mathrm{DH}$ prior to testing resulted in impaired contextual memory retrieval after extinction, eliminating the renewal of conditional responding when animals were tested in a novel, neutral context (AAB renewal). However, if animals were returned to the conditional context during testing (ABA renewal), the context-specificity was minimally affected by hippocampal inactivation, which is consistent with the earlier lesion results (Wilson et al., 1995; Frohardt et al., 2000). It is therefore interesting to understand why the hippocampus plays a role in $\mathrm{ABB}$ or $\mathrm{ABC}$ renewal, but not in ABA renewal. One possibility Corcoran and Maren (2004) proposed is that the ambiguity in the relationship between the test context and the CS in different renewal conditions is not the same, and this may be differentially sensitive to hippocampal manipulations. Therefore, ABA renewal is not susceptible to hippocampal impairments because the testing context reliably predicts the CS-US association and thus has an unambiguous relationship with the CS. By contrast, in $A A B$ and $\mathrm{ABC}$ tests, the context has no history of CS exposure, and therefore the meaning of the CS in testing contexts is ambiguous. This may yield more interference between the retrieval of CS-US and CS-"no US" memories and thus results in more susceptibility to hippocampal disruption.

In a subsequent study, Ji and Maren (2005) further compared the nature and timing of the hippocampal lesions in determining their influence on different renewal paradigms. They made electrolytic lesions of the DH either before conditioning or after extinction, and examined their effects on context-specific expression of fear memory after extinction. The results showed that DH lesions impaired the context-dependence of extinction, independent on whether lesions were made prior to conditioning or after extinction, and independent on whether retrieval testing returned to the conditioning context (ABA renewal) or occurred in a neutral context (AAB renewal). These data are consistent with the inactivation reports (Corcoran and Maren, 2001, 2004), indicating a critical role for the hippocampus in contextual fear memory retrieval. On the other hand, these results are in contrast to lesion studies (Wilson et al., 1995; Frohardt et al., 2000), which demonstrate unaffected ABA renewal by pretraining fornix or hippocampus lesions. One possible interpretation for the disparities, for example, may be that Bouton and colleague used bar-suppression (Wilson et al., 1995; Frohardt et al., 2000), whereas Ji and Maren (2005) used freezing to index fear. These responses have been demonstrated to be neuroanotomically dissociated, and rats can continue to suppress bar pressing in the absence of freezing under some conditions (Amorapanth et al., 1999).

Interestingly, $\mathrm{ABA}$ renewal is not affected by hippocampal inactivation, which is inconsistent with the results showed by Ji and Maren (2005). One possibility to account for this discrepancy may be that the electrolytic lesions clearly disrupt more neurochemical systems than muscimol alone (Ji and Maren, 2005). Another possibility may be the difference in the effects between pretraining and pretesting hippocampal manipulations on the contextual memory retrieval as suggested by Maren et al. (1997). This possibility has been supported by a recent study showing that hippocampal inactivation impaired renewal of fear regardless of testing context occurred when the inactivation was conducted before extinction training (Corcoran et al., 2005).

Nonetheless, the findings from permanent lesions ( $\mathrm{Ji}$ and Maren, 2005) are consistent with the studies with pharmacological inactivation of DH (Corcoran and Maren, 2001, 2004), suggesting the critical requirement of $\mathrm{DH}$ in using contextual stimuli to regulate the expression of fear to a Pavlovian CS after extinction. Based on Bouton's extinction model (Bouton, 1994), Maren and Holt (2000) have posited a model to illustrate hippocampus engagement in latent inhibition (LI). According to Maren and Holt (2000), the DH is necessary for the contextual "gating" of inhibitory CS-"no event" associations in LI. Extinction and LI are similar phenomena in that contextual retrieval cues disambiguate conflicting CS memories and guide behavior. Therefore, this model is also suitable to reveal a role for the $\mathrm{DH}$ in contextual "gating" of inhibitory CS-"no US" association in extinction. In this model, the functional hippocampus allows contextual gating of the inhibitory association, leading to the 
expression of CS-"no US" association memory in the extinction context. This contextual gating of the CS-"no US" association, however, is mitigated by the absence of a functional hippocampus. Hence, the expression of the CS- "no US" memory becomes context-independent, and conditional responding to the CS is reduced in all test contexts.

\section{Hippocampal involvement in encoding context-specificity of extinction}

Collectively, it seems that one function of the hippocampus is to control the context-specific expression of extinction. But it still remains unclear whether the hippocampus is also required to encode extinction or the context-specificity of extinction. To address this question, recent work has investigated the impact of pre-extinction inactivation of the $\mathrm{DH}$ by muscimol on encoding the context specificity of extinction (Corcoran et al., 2005). DH inactivation prior to extinction training attenuated extinction learning and disrupted contextual encoding of extinction memory. Rats that underwent extinction training after hippocampal inactivation showed renewal of fear irrespective of the context, in which testing context occurred. Therefore, it appears that the hippocampus plays a role in acquiring extinction, and is required in encoding the CS-context relationship to guide behavior after extinction. Similarly, the contextdependency of extinction was abolished by hippocampal inactivation when muscimol was administered before testing. Interestingly, it did so by diminishing renewal of fear when retrieval occurred outside of extinction context. This contrasted with those rats treated with muscimol before extinction, which exhibited renewal of fear, independent of the context, in which retrieval testing took place (Corcoran et al., 2005). The reasons for the differential effects between pre- and post-extinction hippocampal inactivation on context-specificity of extinction might be due to different hippocampal mechanisms. Corcoran et al. (2005) argued that when hippocampus is engaged in encoding context-specificity of extinction, it plays a role in mediating negative occasion setting, which signals the CS-"no US" associations in extinction as suggested by Holland et al. (1999). A deficit in an occasion-setting process produced by hippocampal inactivation prior to extinction would engender the rats' inability to retrieve extinction memories in the contexts, in which they were learned. However, this model does not account for the effects of pretesting hippocampal inactivation on contextspecific expression of extinction. Instead, it is because hippocampal inactivation removes the contextual gating and thus cause the extinction memory to prevail during retrieval (Holt and Maren, 1999; Maren and Holt, 2000), leading to conditional responding reduced in all contexts.

This study, along with previous data, further elaborates an important role for the hippocampus in mediating contextual control of extinction. In addition to animal research, there is emerging evidence indicating hippocampal involvement in mediating context-dependent human extinction memory (Charney et al., 1993; Mineka and Zinbarg, 1996; LaBar and Phelps, 2005; Kalisch et al., 2006). For example, many patients with anxiety disorders, including phobias and PTSD, are characterized by hippocampal dysfunction and inappropriate context control of the expression of acquired fear response. Recently, Kalisch et al. (2006) examined context-dependent retrieval of human extinction memory with the use of fMRI. They showed that CS-evoked brain activity is context-dependent, and this context-dependent brain activity specifically exhibited in ventromedial prefrontal cortex (vmPFC) and the hippocampus. Also, this activity positively correlated between vmPFC and hippocampus. The role of the hippocampus as supporting context-dependent retrieval of extinction memory has also been strengthened by the finding of impaired context-specific reinstatement in two patients (LaBar and Phelps, 2005). In this report, LaBar and Phelps (2005) used environmental cues as context to investigate how it regulates recovery of conditional fear following extinction. The results showed the context-specificity in the recovery of extinguished fear response after reinstating shock in normal participants. However, two amnesic patients with bilateral ischemic hippocampal damage failed to exhibit recovery following reinstatement in the same context after extinction, despite performing intact fear acquisition and extinction. These results suggest that human hippocampus not only provides for context-dependent retrieval of extinction memory, but also is essential in this memory retrieval.

\section{Amygdala}

Although the earlier data suggest an important role for the hippocampus in mediating the contextual modulation of extinction, extinction memory is not stored in the hippocampus. Instead, evidence from animal and human studies indicates that the amygdala is involved in the acquisition and extinction of fear memory (Maren et al., 1996; Rogan and LeDoux, 1996; Goosens et al., 2003; for review, see Davis et al., 1994; Maren, 2001; Sotres-Bayon et al., 2004), and seems to have a pivotal role in the extinction of learned fear (Falls et al., 1992; Lu et al., 2001; for review, see Walker and Davis, 2002; Sotres-Bayon et al., 2004). The mediation of extinction by the amygdala is manifested in the firing of lateral amygdala (LA) neurons. The neuronal activity of LA encodes conditional fear memories and is correlated with the behavioral responses to a fearful CS (Maren, 2000; for review see, Maren and Quirk, 2004). Therefore, it is reasonable to hypothesize that amygdala neuronal activity would be contextually modulated after extinction training, as well as that a renewal of fear occurs in the animal's behavioral performance. In addition, the hippocampus would contribute to the context regulated effects for the CS-evoked neuronal activity.

To test this idea, Hobin et al. (2003) trained rats using a fear extinction procedure that yields context-specific memories for two different CSs, in which they could record CS-elicited firing in LA neurons in two different contexts. The results of this experiment showed that LA neuronal activity exhibited context-dependent spike firing, in that CS-evoked LA firing responded more to the CS when presented outside of extinc- 
tion context, compared with CS-evoked firing observed when the same CS was tested in its own extinction context. Similarly, conditional freezing was context-dependent, in which rats demonstrated renewal of fear to an extinguished CS when tested in a context different from extinction (Hobin et al., 2003). In addition, rats with hippocampal inactivation prior to testing were incapable of being recorded the context-dependent spike firing, in that they lost the ability to get the renewal of CSevoked LA responses that normally observed in intact rats (Maren and Hobin, 2007). In this case, CS-evoked LA neuronal activity diminished in all contexts, which matches the pattern of behavioral performance modulated by context after hippocampal inactivation that was previously reported (Corcoran and Maren, 2001, 2004).

\section{Hippocampus-prefrontal cortex-amygdala interactions}

Collectively, these data suggest that context-dependent neuronal activity in the LA may be an important mechanism for disambiguating the meaning of fear signals, thereby enabling appropriate behavioral responses to such stimuli. This contextual modulation of amygdala neuronal activity requires a functional hippocampus to implement. However, it is not clear what the mechanisms are, by which the hippocampus interacts with the amygdale, to regulate CS-evoked firing and contextspecific behavioral response. Because there are reciprocal connections between amygdala and hippocampus (Maren and Fanselow, 1995; Pitkanen et al., 2000), one model suggests that a direct projection from hippocampus to LA subserves contextual modulation of neuronal activity (Maren and Quirk, 2004). Alternatively, the medial prefrontal cortex (mPFC) has been anatomically identified to receive strong hippocampal projection, and exerts strong inhibitory control over the amygdala (Jay and Witter, 1991; Conde et al., 1995; Rosenkranz and Grace, 1999, 2001, 2002; Ishikawa and Nakamura, 2003; for review, see Tamminga, 2006), substantial evidence suggests that mPFC plays a critical role in the representation of fear extinction (Quirk et al., 2000; Milad and Quirk, 2002; for review, see Stotres-Bayon et al., 2004; Quirk et al., 2006), and hippocampal modulation of mPFC may control LA projections to the central amygdala (Thierry et al., 2000; Hobin et al., 2003; Sotres-Bayon et al., 2004). This model proposes that the hippocampus performs an executive role in the balance of excitation and inhibition in the fear circuits, in which MPFC may come to inhibit LA neuronal activity during fear extinction that otherwise excite fear response (Hobin et al., 2003; SotresBayon et al., 2004; Maren, 2005). Also, the regulation of this fear is dependent on the context, in which fear stimuli are encountered (Hobin et al., 2003; Maren, 2005). When animals are tested in the extinction context, the hippocampus drives mPFC inhibition of LA. However, if animals are presented with an extinguished CS outside the extinction context, the hippocampus may inhibit mPFC activation and thus promote excitation in the LA to renew extinguished fear under these conditions (Hobin et al., 2003; Maren, 2005). This point of view is supported by a recent study in humans demonstrating that CS-evoked brain activity is context-dependent after extinction, and this activity is particularly observed in vmPFC and the hippocampus (Kalisch et al., 2006). In addition, CS-evoked in the hippocampus and the vmPFC is positively correlated, which is consistent with the view that the hippocampus may confer contextual information to vmPFC during the expression of extinction (Hobin et al., 2003; Kalisch et al., 2006).

Although the network of the hippocampus, prefrontal cortex, and amygdala is involved in regulating conditional response performance after extinction (Hobin et al., 2003; Maren and Quirk, 2004; Maren, 2005), it is not clear what causes the hippocampus to be activated when the CS is presented outside the extinction context. It is also unclear whether the prefrontal cortex itself is engaged in the context-dependency of extinction, and if so, how prefrontal cortex uses the contextual information to regulate extinction memories. Thus, there is considerable work to do to uncover the brain mechanisms that underlie the contextual control of extinction.

\section{CONCLUSION}

In summary, a variety of research indicates that responding to an extinguished CS is susceptible to many recovery effects, suggesting that extinction involves new learning, and this new learning is especially sensitive to manipulations of context. Substantial evidence supports a critical role for the hippocampus in mediating contextual control of extinction. These data reveal that the $\mathrm{DH}$ is involved in the acquisition, contextual encoding, and context-dependent retrieval of fear extinction (Corcoran et al., 2005; Ji and Maren, 2004). Moreover, emerging evidence suggests that the context-dependence of extinguished fear involves the interactions between the hippocampus, amygdala, and prefrontal cortex (Hobin et al., 2003). Although the hippocampus plays an important role in the contextual modulation of extinction, it is not required for storing extinction memories. Instead, the amygdala appears to be a critical site for storing and expressing of fear extinction, and mPFC may play a critical role in regulating the expression of fear extinction by inhibiting the amygdala. The hypothesis that LA neurons encode fear memories and CS-elicited LA firing is contextually modulated after extinction has been demonstrated to require the functional hippocampus. According to this result, it has been proposed that contextual modulation of CS-evoked spike firing could be implemented by hippocampal modulation of mPFC to exert control over the amygdala (Hobin et al., 2003; Maren and Quirk, 2004; Sotres-Bayon et al., 2004). Alternatively, direct projections from the hippocampus to the amygdala may regulate fear expression after extinction (Maren and Quirk, 2004). Because the hippocampus has strong reciprocal connections with mPFC and the amygdala, it is yet unclear, which of these connections is important for the contextual modulation of extinction. Nevertheless, it is without doubt that the hippocampus plays a central role in contextual control of fear extinction. 


\section{Acknowledgments}

The authors would like to thank Ewelina Knapska and April Qian for editing on an earlier draft of the manuscript.

\section{REFERENCES}

Ahlers ST, Richardson R. 1985. Administration of dexamethasone prior to training blocks ACTH-induced recovery of an extinguished avoidance response. Behav Neurosci 99:760-764.

Amorapanth P, Nader K, LeDoux JE. 1999. Lesions of periaqueductal gray dissociate-conditioned freezing from conditioned suppression behavior in rats. Learn Mem 6:491-499.

Anagnostaras SG, Maren S, Fanselow MS. 1999. Temporally graded retrograde amnesia of contextual fear after hippocampal damage in rats: Within-subjects examination. J Neurosci 19:1106-1114.

Baker AG, Steinwald H, Bouton ME. 1991. Contextual conditioning and reinstatement of extinguished instrumental responding. Q J Exp Psychol B 43:199-218.

Bouton ME. 1984. Differential control by context in the inflation and reinstatemen paradigms. J Exp Psychol Anim Behav Process 10: 56-74.

Bouton ME. 1993. Context, time, and memory retrieval in the interference paradigms of Pavlovian conditioning. Psychol Bull 114:8099.

Bouton ME. 1994. Context, ambiguity, and classical conditioning. Curr Dir Psychol Sci 3:49-53.

Bouton ME. 2002. Context, ambiguity, and unlearning: Sources of relapse after behavioral extinction. Biol Psychiatry 52:976-986.

Bouton ME. 2004. Context and behavioral processes in extinction. Learn Mem 11:485-494.

Bouton ME, Bolles RC. 1979a. Contextual control of the extinction of conditioned fear. Learn Motiv 10:445-466.

Bouton ME, Bolles RC. 1979b. Role of conditioned contextual stimuli in reinstatement of extinguished fear. J Exp Psychol Anim Behav Processes 5:368-378.

Bouton ME, García-Gutiérrez A. 2006. Intertrial interval as a contextual stimulus. Behav Processes 71:307-317.

Bouton ME, King DA. 1983. Contextual control of the extinction of conditioned fear: Tests for the associative value of the context. J Exp Psychol Anim Behav Process 9:248-265.

Bouton ME, King DA. 1986. Effect of context on performance to conditioned stimuli with mixed histories of reinforcement and nonreinforcement. J Exp Psychol Anim Behav Process 12:4-15.

Bouton ME, Swartzentruber D. 1986. Analysis of the associative and occasion-setting properties of contexts participating in a Pavlovian discrimination. J Exp Psychol Anim Behav Process 12: 333-350.

Bouton ME, Swartzentruber D. 1989. Slow reacquisition following extinction: Context encoding and retrieval mechanisms. J Exp Psychol Anim Behav Process 15:43-53.

Bouton ME, Kenney FA, Rosengard C. 1990. State-dependent fear extinction with two benzodiazepine tranquilizers. Behav Neurosci 104:44-55.

Bouton ME, Westbrook RF, Corcoran KA, Maren S. 2006. Contextual and temporal modulation of extinction: Behavioral and biological mechanisms. Biol Psychiatry 60:352-360.

Brooks DC. 2000. Recent and remote extinction cues reduce spontaneous recovery. Q J Exp Psychol B 53:25-58.

Brooks DC, Bouton ME. 1993. A retrieval cue for extinction attenuates spontaneous recovery. J Exp Psychol Anim Behav Process 19: 77-89.

Brooks DC, Bouton ME. 1994. A retrieval cue for extinction attenuates response recovery (renewal). caused by a return to the conditioning context. J Exp Psychol Anim Behav Process 20: 366-379.

Brooks DC, Karamanlian BR, Foster V. 2001. Extinction and spontaneous recovery of ataxic tolerance to ethanol in rats. Psychopharmacol 153:491-496.

Burgess N, Maguire EA, O'Keefe J. 2002. The human hippocampus and spatial and episodic memory. Neuron 35:625-641.

Charney DS, Deutsch AY, Krystal JH, Southwick SM, Davis M. 1993. Psychobiologic mechanisms of posttraumatic stress disorder. Arch Gen Psychiatry 50:295-305.

Chelonis JJ, Calton JL, Hart JA, Schachtman TR. 1999. Attenuation of the renewal effect by extinction in multiple contexts. Learn Motiv 30:1-14.

Conde F, Maire-Lepoivre E, Audinat E, Crepel F. 1995. Afferent connections of the medial frontal cortex of the rat. II. Cortical and subcortical afferents. J Comp Neurol 352:567-593.

Corcoran KA, Maren S. 2001. Hippocampal inactivation disrupts contextual retrieval of fear memory after extinction. J Neurosci 21:1720-1726.

Corcoran KA, Maren S. 2004. Factors regulating the effects of hippocampal inactivation on renewal of conditional fear after extinction. Learn Mem 11:598-603.

Corcoran KA, Desmond TJ, Frey KA, Maren S. 2005. Hippocampal inactivation disrupts the acquisition and contextual encoding of fear extinction. J Neurosci 25:8978-8987.

Cunningham CL. 1979. Alcohol as a cue for extinction: State dependency produced by conditioned inhibition. Anim Learn Behav 7: 45-52.

Davis M, Rainnie D, Cassell M. 1994. Neurotransmission in the rat amygdala related to fear and anxiety. Trends Neurosci 17:208214.

Delamater AR. 2004. Experimental extinction in Pavlovian conditioning: Behavioural and neuroscience perspectives. Q J Exp Psychol B 57:97-132.

Denniston JC, Chang RC, Miller RR. 2003. Massive extinction treatment attenuates the renewal effect. Learn Motiv 34:68-86.

Eichenbaum H. 2000. A cortical-hippocampal system for declarative memory. Nat Rev Neurosci 1:41-50.

Eichenbaum H. 2001. The hippocampus and declarative memory: Cognitive mechanisms and neural codes. Behav Brain Res 127: 199-207.

Falls WA, Miserendino MJ, Davis M. 1992. Extinction of fear-potentiated startle: Blockade by infusion of an NMDA antagonist into the amygdala. J Neurosci 12:854-863.

Fanselow MS. 2000. Contextual fear, gestalt memories, and the hippocampus. Behav Brain Res 110:73-81.

Feldner MT, Monson CM, Friedman MJ. 2007. A critical analysis of approaches to targeted PTSD prevention: Current status and theoretically derived future directions. Behav Modif 31:80-116.

Friedman MJ, Schnurr PP, McDonagh-Coyle A. 1994. Post-traumatic stress disorder in the military veteran. Psychiatr Clin North Am 17:265-277.

Frohardt RJ, Guarraci FA, Bouton ME. 2000. The effects of neurotoxic hippocampal lesions on two effects of context after fear extinction. Behav Neurosci 114(2):227-240.

Good M, Honey RC. 1991. Conditioning and contextual retrieval in hippocampal rats. Behav Neurosci 105:499-509.

Goosens KA, Hobin JA, Maren S. 2003. Auditory-evoked spike firing in the lateral amygdala and Pavlovian fear conditioning: Mnemonic code or fear bias? Neuron 40:1013-1022.

Gunther LM, Denniston JC, Miller RR. 1998. Conducting exposure treatment in multiple contexts can prevent relapse. Behav Res Ther 36:75-91.

Haberlandt K, Hamsher K, Kennedy AW. 1978. Spontaneous recovery in rabbit eyelid conditioning. J Gen Psychol 98:241-244.

Hirsh R. 1974. The hippocampus and contextual retrieval of information from memory: A theory. Behav Biol 12:421-444. 
Hirsh R. 1980. The hippocampus, conditional operations, and cognition. Physiol Psychol 8:175-182.

Hobin JA, Goosens KA, Maren S. 2003. Context-dependent neuronal activity in the lateral amygdala represents fear memories after extinction. J Neurosci 23:8410-8416.

Holland PC. 1992. Occassion setting in Paviovian conditioning. In: Medin DL, editor. The psychology of learning and motivation, Vol. 28. Academic Press, San Diego, CA. pp. 69-125.

Holland PC, Lamoureux JA, Han J-S, Gallagher M. 1999. Hippocampal lesions interfere with pavlovian negative occasion setting. Hippocampus 9:143-157.

Holt WG, Maren S. 1999. Muscimol inactivation of the dorsal hippocampus impairs contextual retrieval of fear memory. J Neurosci 19:9054-9062.

Honey RC, Good M. 1993. Selective hippocampal lesions abolish the contextual specificity of latent inhibition and conditioning. Behav Neurosci 107:23-33.

Ishikawa A, Nakamura S. 2003. Convergence and interaction of hippocampal and amygdalar projections within the prefrontal cortex in the rat. J Neurosci 23:9987-9995.

Jay TM, Witter MP. 1991. Distribution of hippocampal CA1 and subicular efferents in the prefrontal cortex of the rat studied by means of anterograde transport of Phaseolus vulgaris-leucoagglutinin. J Comp Neurol 313:574-586.

Ji J, Maren S. 2005. Electrolytic lesions of the dorsal hippocampus disrupt renewal of conditional fear after extinction. Learn Mem 12:270-276.

Kalisch R, Korenfeld E, Stephan KE, Weiskopf N, Seymour B, Dolan RJ. 2006. Context-dependent human extinction memory is mediated by a ventromedial prefrontal and hippocampal network. J Neurosci 26:9503-9511.

Kim JJ, Fanselow MS. 1992. Modality-specific retrograde amnesia of fear. Science 256:675-677.

Kim JJ, Jung MW. 2006. Neural circuits and mechanisms involved in Pavlovian fear conditioning: A critical review. Neurosci Biobehav Rev 30:188-202.

LaBar KS, Phelps EA. 2005. Reinstatement of conditioned fear in humans is context dependent and impaired in amnesia. Behav Neurosci 119:677-686.

Lu KT, Walker DL, Davis M. 2001. Mitogen-activated protein kinase cascade in the basolateral nucleus of amygdala is involved in extinction of fear-potentiated startle. J Neurosci 21: RC162.

Maren S. 2000. Auditory fear conditioning increases CS-elicited spike firing in lateral amygdala neurons even after extensive overtraining. Eur J Neurosci 12:4047-4054.

Maren S. 2001. Neurobiology of Pavlovian fear conditioning. Annu Rev Neurosci 24:897-931.

Maren S. 2005. Building and burying fear memories in the brain. Neuroscientist 11:89-99.

Maren S, Chang H. 2006. Recent fear is resistant to extinction. Proc Natl Acad Sci USA 103:18020-18025.

Maren S, Fanselow MS. 1995. Synaptic plasticity in the basolateral amygdala induced by hippocampal formation stimulation in vivo. J Neurosci 15:7548-7564.

Maren S, Hobin JA. 2007. Hippocampal regulation of context-dependent neuronal activity in the lateral amygdala. Learn Mem 14:318-324.

Maren S, Holt W. 2000. The hippocampus and contextual memory retrieval in Pavlovian conditioning. Behav Brain Res 110:97-108.

Maren S, Quirk GJ. 2004. Neuronal signalling of fear memory. Nat Rev Neurosci 5:844-852.

Maren S, Aharonov G, Stote DL, Fanselow MS. 1996. N-Methyl-Daspartate receptors in the basolateral amygdala are required for both acquisition and expression of conditional fear in rats. Behav Neurosci 110:1365-1374.

Maren S, Aharonov G, Fanselow M. 1997. Neurotoxic lesions of the dorsal hippocampus and Pavlovian fear conditioning in rats. Behav Brain Res 88:261-274.
Milad MR, Quirk GJ. 2002. Neurons in medial prefrontal cortex signal memory for fear extinction. Nature 420:70-74.

Mineka S, Zinbarg R. 1996. Conditioning and ethological models of anxiety disorders: Stress-in-dynamic context anxiety models. In: Hope DA, editor. Nebraska Symposium on Motivation, 1995: Vol. 43. Perspectives on Anxiety, Panic, and Fear. Current Theory and Research in Motivation. Lincoln: University of Nebraska Press. pp $135-210$.

Mineka S, Mystkowski JL, Hladek D, Rodriguez BI. 1999. The effects of changing contexts on return of fear following exposure therapy for spider fear. J Consult Clin Psychol 167:599-604.

Myers KM, Davis M. 2002. Behavioral and neural analysis of extinction. Neuron 36:567-584.

Nakajima S, Tanaka K, Urshihara H, Imada H. 2000. Renewal of extinguished lever-press responses upon return to the training context. Learn Motiv 31:416-431.

O'Reilly RC, Rudy JW. 2001. Conjunctive representations in learning and memory: Principles of cortical and hippocampal function. Psychol Rev 108:311-345.

Pavlov IP. 1927. Conditioned reflexes. London: Oxford University Press.

Pearce JM, Hall G. 1980. A model for Pavlovian conditioning: Variations in the effectiveness of conditioned but not unconditioned stimuli. Psychol Rev 87:332-352.

Phillips RG, LeDoux JE. 1992. Differential contribution of amygdala and hippocampus to cued and contextual fear conditioning. Behav Neurosci 106:274-285.

Pitkanen A, Pikkarainen M, Nurminen N, Ylinen A. 2000. Reciprocal connections between the amygdala and the hippocampal formation, perirhinal cortex, and postrhinal cortex in rat. A review. Ann NY Acad Sci 911:369-391.

Quirk GJ. 2002. Memory for extinction of conditioned fear is longlasting and persists following spontaneous recovery. Learn Mem 9:402-407.

Quirk GJ, Russo GK, Barron JL, Lebron K. 2000. The role of ventromedial prefrontal cortex in the recovery of extinguished fear. J Neurosci 20:6225-6231.

Quirk GJ, Garcia R, Gonzalez-Lima F. 2006. Prefrontal mechanisms in extinction of conditioned fear. Biol Psychiatry 60:337-343.

Rauhut AS, Thomas BL, Ayres JJB. 2001. Treatments that weaken Pavlovian conditioned fear and thwart its renewal in rats: Implications for treating human phobias. J Exp Psychol Anim Behav Processes 27:99-114.

Rescorla RA. 2004. Spontaneous recovery. Learn Mem 11:501-509.

Rescorla RA, Heth CD. 1975. Reinstatement of fear to an extinguished conditioned stimulus. J Exp Psychol Anim Behav Process $1: 88-96$.

Rescorla RA, Wagner AR. 1972. A theory of Pavlovian conditioning: Variations in the effectiveness of reinforcement and nonreinforcement. In: Black AH, Pokasy WK, editors. Classical Conditioning. II. Current Research and Theory (pp. 66-99). New York: AppletonCentury-Crofts.

Richardson R, Riccio DC, Devine L. 1984. ACT H-induced recovery of extinguished avoidance responding. Physiol Psycyol 12, 184-192.

Robbins SJ. 1990. Mechanisms underlying spontaneous recovery in autoshaping. J Exp Psychol Anim Behav Processes 16:235-249.

Rodriguez BI, Craske MG, Mineka S, Hladek D. 1999. Context-specificity of relapse: Effects of therapist and environmental context on return of fear. Behav Res Ther 37:845-862.

Rogan MT, LeDoux JE. 1996. Emotion: Systems, cells, synaptic plasticity. Cell 85:469-475.

Rosas JM, Bouton ME. 1998. Context change and retention interval can have additive rather than interactive effects after taste aversion extinction. Psychonomic Bull Rev 5:79-83.

Rosas JM, Vila NJ, Lugo M, López L. 2001. Combined effect of context change and retention interval on interference in causality judgments. J Exper Psychol Anim Behav Processes 27:153164. 
Rosenkranz JA, Grace AA. 1999. Modulation of basolateral amygdala neuronal firing and afferent drive by dopamine receptor activation in vivo. J Neurosci 19:11027-11039.

Rosenkranz JA, Grace AA. 2001. Dopamine attenuates prefrontal cortical suppression of sensory inputs to the basolateral amygdala of rats. J Neurosci 21:4090-4103.

Rosenkranz JA, Grace AA. 2002. Cellular mechanisms of infralimbic and prelimbic prefrontal cortical inhibition and dopaminergic modulation of basolateral amygdala neurons in vivo. J Neurosci 22:324-337.

Ross RT, Orr WB, Holland PC, Berger TW. 1984. Hippocampectomy disrupts acquisition and retention of learned conditional responding. Behav Neurosci 98:211-225.

Rudy JW, O’Reilly RC. 1999. Contextual fear conditioning, conjunctive representations pattern completion, and the hippocampus. Behav Neurosci 113:867-880.

Rudy JW, O'Reilly RC. 2001. Conjunctive representations, the hippocampus, and contextual fear conditioning. Cogn Affect Behav Neurosci 1:66-82.

Sotres-Bayon F, Bush DE, LeDoux JE. 2004. Emotional perseveration: An update on prefrontal-amygdala interactions in fear extinction. Learn Mem 11:525-535.
Spear NE. 1981. Extending the domain of memory retrieval. In: Spear NE, Miller RR, editors. Information Processing in Animals: Memory Mechanisms. Hillsdale, NJ: Lawrence Erlbaum Associates. pp 341-378.

Squire LR, Zola SM. 1996. Structure and function of declarative and nondeclarative memory systems. Proc Natl Acad Sci USA 93:1351513522.

Tamminga CA. 2006. The anatomy of fear extinction. Am J Psychiatry 63:961.

Thierry AM, Gioanni Y, Degenetais E, Glowinski J. 2000. Hippocampo-prefrontal cortex pathway: Anatomical and electrophysiological characteristics. Hippocampus 10:411-419.

Wagner AR, Brandon SE. 1989. Evolution of a structured connectionist model of Pavlovian conditioning (AESOP). In: Klein SB, Mowrer RR, editors. Contemporary Learning Theories: Pavlovian Conditioning and the Status of Traditional Learning Theory. Hillsdale, NJ: Lawrence Erlbaum Associates. pp 149-189.

Walker DL, Davis M. 2002. The role of amygdala glutamate receptors in fear learning, fear-potentiated startle, and extinction. Pharmacol Biochem Behav 71:379-392.

Wilson A, Brooks DC, Bouton ME. 1995. The role of the rat hippocampal system in several effects of context in extinction. Behav Neurosci 109:828-836. 